\title{
Molecular alterations and clinical relevance in cervical carcinoma and precursors (Review)
}

\author{
JIAYI SHENG ${ }^{1}$, YI XIANG ${ }^{1}$, LI SHANG ${ }^{2}$ and QIONGQIONG HE ${ }^{1,2}$ \\ ${ }^{1}$ School of Basic Medical Science, Central South University, Changsha, Hunan 410013; \\ ${ }^{2}$ Department of Pathology, Xiangya Hospital, Central South University, Changsha, Hunan 410008, P.R. China
}

Received May 19, 2020; Accepted September 22, 2020

DOI: 10.3892/or.2020.7804

\begin{abstract}
Cervical cancer is one of the most common types of cancer and the fourth leading cause of cancer-related deaths in women. The occurrence and development of cervical cancer is a multifactorial and multilevel process, which usually occurs alongside a continuous high-risk human papillomavirus infection. With further developments in molecular biology and the advancement of sequencing technology, the role of biomarkers in cervical diseases has been gradually recognized. Therefore, it remains a priority to identify key molecular markers that can be used for the screening and triaging of the lesions. In recent years, numerous studies have been conducted in order to identify important markers for cervical diseases. The present review aimed to summarize the molecular alterations and clinical relevance of chromosomal alterations, DNA polymorphisms, the DNA methylation status, histone modifications, and alterations in microRNA and protein expression levels. Accumulating evidence suggests that molecular alterations may reflect the degree and the prognosis of the disease. Although significant progress has been made in the field of cervical cancer research, further samples and experiments are still required to identify crucial molecules.
\end{abstract}

\section{Contents}

1. Introduction

2. Chromosomal alterations

3. DNA polymorphisms

4. DNA methylation

5. Histone modifications

Correspondence to: Professor Qiongqiong He, School of Basic Medical Science, Central South University, 172 Tongzipo Road, Changsha, Hunan 410013, P.R. China

E-mail: qiongqionghe@csu.edu.cn

Dr Li Shang, Department of Pathology, Xiangya Hospital, Central South University, 87 XiangYa Road, Changsha, Hunan 410008, P.R. China

E-mail: shangli1212@csu.edu.cn

Key words: cervical cancer, cervical squamous intraepithelial lesions, precursors, biomarkers, molecules
6. miRNA alterations

7. Protein alterations

8. Conclusion

\section{Introduction}

Cervical cancer is one of the ten most common types of malignancies affecting women. According to the cancer statistics in 2018, there are $~ 570,000$ new cases of cervical cancer and 311,000 deaths due to cervical cancer worldwide each year (1). In addition, Chinese cancer data have estimated $\sim 98,500$ cases and 30,500 deaths from cervical cancer, accounting for $17 \%$ of cases and $10 \%$ of deaths globally. Contrary to the decreasing trend of morbidity in developed countries, the incidence rates of cervical cancer in China have increased significantly since 2000 (2).

The major histological type of cervical cancer is squamous carcinoma of the cervix (SCC). SCC has been confirmed to be caused by high-risk human papillomavirus (HR-HPV) infection. Half of HPV infections are cleared within 6-12 months; however, $10 \%$ of HPV infections persist (3). Following HR-HPV infection, cervical cells may undergo the precursor steps of SCC, which are termed squamous intraepithelial lesions (SILs) (4). SILs are classified into low grade SILs (LSILs) and high grade SILs (HSILs), which correspond to the traditional histological classification, known as cervical intraepithelial neoplasia (CIN). CIN1 is the synonym for LSIL, and CIN2 and CIN3 are classified as HSILs (5). The histological diagnosis of CIN is the gold standard to guide subsequent treatment; however, the reproducibility of CIN diagnosis is poor, especially for CIN2, with a diagnostic consistency rate of $<50 \%$ (6). Moreover, the prognosis of $\mathrm{CIN}$ is different. According to a survey, the 10 -year transition probability from CIN1 to CIN2 was $4.37 \%$, and from CIN2 to $\mathrm{CIN3}^{+}$was $25.58 \%$ (7). In addition, a recent meta-analysis revealed that the regression rate of CIN2 after a 24-month follow-up was 50\% (11 studies, 819/1,470 women) and 60\% (4 studies, 638/1,069 women, age $<30$ years), respectively. Patients with CIN2 who have a plan for future pregnancies can attend screening tests and there is no requirement for immediate treatment (8).

It is imperative to identify molecular markers for the screening and triage of cervical cancer and precancerous lesions. For patients with cervical precancerous lesions, 
the identified biomarkers may predict the development of the disease and help to guide subsequent treatments and avoid overtreatment. For patients with cervical cancer, the biomarkers could help to predict the prognosis and potentially be used as therapeutic targets.

For both cervical cancer and precursors lesions, the majority of previous research has investigated the molecular alterations and clinical relevance using PCR, fluorescence in situ hybridization, microarrays, ELISAs, western blotting and immunohistochemistry. The present review aimed to provide a summary of the progression of cervical cancer and precursor lesions due to the alteration of chromosomes, DNA polymorphisms, the DNA methylation status, histone modifications, and alterations in the expression levels of microRNAs (miRNAs) and proteins.

\section{Chromosomal alterations}

The presence of chromosomal aberrations has been confirmed in SCC and its precursors. For example, Policht et al (9) reported the gain or loss in copies of 8q24, Xp22, 20q13, 3p14, 3q26 and CEP15 in the cervical tissue of CIN and cancer lesions, and it was further reported that 8q24 and 3q26 were the most useful molecules for detecting HSILs and SCCs. Rodolakis et al (10) analyzed the gain of 3q26 in 40 patients and discovered that none of the $3 \mathrm{q} 26(-)$ progressed to HSILs/CIN2 ${ }^{+}$after 17.5 months, while $38 \%$ of the $3 \mathrm{q} 26(+)$ patients progressed. The study also revealed that the gain of $3 \mathrm{q} 26$ could predict the progression with a negative predictive value (NPV) of $100 \%$. Another meta-analysis indicated a potential association between the gain of 3q26 and disease prognosis ( 8 studies, 407 patients), with positive predictive values ranging from 50 to $93 \%$ and a NPV ranging from 75 to $100 \%$ (11). In addition to $3 \mathrm{q} 26$, gains in $5 \mathrm{p} 15$ were also identified in cervical lesions of increasing severity (12). Based on the above findings, $3 \mathrm{q} 26$ was hypothesized to have an important role in cervical cancer and it should be further studied. The details of these molecules are presented in Table I.

\section{DNA polymorphisms}

DNA polymorphisms are a type of genetic variation that do not change the gene expression levels. Cezar-Dos-Santos et al (13) reported that the forkhead box P3 (FOXP3) rs3761548 homozygous genotype may be associated with the resistance to HPV infection, while the rs2232365 homozygous genotype $(\mathrm{G} / \mathrm{G})$ was a risk factor for HPV infection [odds ratio $(\mathrm{OR})=2.10$ (95\% confidence interval (CI): 1.06-4.15)]. In addition, the Arg72Arg genotype and Arg72 alleles of tumor protein p53 (TP53) were also suggested to be related to the susceptibility of HPV infection [OR=1.85 (95\% CI: 1.03-3.32) and 1.94 (95\% CI: 1.20-3.15), respectively] (14).

The relationship between genetic polymorphisms and cervical cancer susceptibility has also been studied. Chen et al (15) suggested that polymerase II polypeptide E (POLR2E) may be associated with the susceptibility of cervical cancer and breast cancer. For Uyghur women, the apolipoprotein B mRNA editing enzyme-catalytic polypeptide-like $3 \mathrm{G}$ (APOBEC $3 G)$ and interleukin-1 $\beta$ (ILIB) polymorphisms were discovered to be associated with the susceptibility of cervical cancer $(16,17)$. For Han Chinese women, the NAD $(\mathrm{P}) \mathrm{H}$ : Quinone oxidoreductase 1 (NQO1) rs1800566 TT genotype presented with an increased risk of cervical cancer development compared with the CT and CC genotypes (18). Notably, there seems to be ethnic differences in the presence of DNA polymorphisms; for instance, according to a meta-analysis, the cytotoxic T-lymphocyte associated antigen-4 (CTLA4) gene rs5742909 polymorphism was related to the susceptibility of cervical cancer in Asians, but it had little association with cervical cancer in Caucasians (19). Similarly, genetic polymorphisms, such as in the deoxyuridine triphosphatase (DUT) gene, were also discovered to be associated with HSIL susceptibility (20). Thus, DNA polymorphisms have been suggested to serve a predictive role for the susceptibility of cervical lesions. Predicting the early occurrence of cervical cancer can help prevent its occurrence, thus it is worthy of research. The details of these findings are presented in Table II.

\section{DNA methylation}

Sakane et al (21) investigated the methylation of distal-less homeobox 4 (DLX4) and SIM bHLH transcription factor 1 (SIM1) in LSILs; significant differences were identified in the methylation frequency of $D L X 4$ and SIM1 between LSILs that persisted for $>1$ year and LSILs that progressed to HSILs within a year $(\mathrm{P}=0.044$ and $\mathrm{P}=0.005$, respectively). LSIL cases with SIM1 methylation were identified to progress to HSILs faster compared with DNA methylation-negative cases $(\mathrm{P}=0.033)$. According to a meta-analysis of 1,055 patients in 7 studies, paired box gene 1 ( $P A X 1)$ methylation was also discovered to be a protective factor for CIN1 to CIN2/3 progression and CIN2/3 to cervical cancer progression, demonstrating an OR of 0.09 and 0.16 , respectively (22). Through studying plasma samples, the methylation of maternally expressed 3 (MEG3) in CIN3 and cervical cancer was identified to be significantly increased compared with that in healthy controls, exhibiting an OR of 13.033 and 17.100 , respectively. In addition, the methylation status of $M E G 3$ was increased in cervical cancer tissues compared with normal tissues, which indicated that the methylation status of $M E G 3$ may have a diagnostic value in plasma and tissues (23).

In another study, the methylation patterns of 15 genes in the normal cervix and CIN1-3 cervixes were analyzed using quantitative methylation-specific PCR. The methylation of hsa-miR-124-2, SRY-box transcription factor 1 (SOXI), telomerase reverse transcriptase (TERT) and LIM homeobox transcription factor 1- $\alpha(L M X 1 A)$ genes were discovered to be independent predictors associated with the diagnosis of high-grade cervical lesions, exhibiting ORs of 5.1, 2.8, 2.2, 2.0, respectively (24). Verlaat et al (25) discovered that the methylation of growth hormone secretagogue receptor (GHSR), somatostatin (SST) and Zic family member 1 (ZICl) were also associated with gain in $3 q$ and an increased severity of cervical lesions ( $\mathrm{P}<0.005)$. Finally, De Strooper et al (26) followed 1,040 HPV-positive women for 14 years and discovered that women with negative family with sequence similarity 19 (chemokine (C-C)-motif)-like)-member A4 (FAM19A4)/miR-124-2 methylation had a lower risk of cervical cancer. The findings described above are presented in Table III. 
Table I. Chromosomal alterations in cervical disease.

\begin{tabular}{|c|c|c|c|c|c|c|}
\hline Name & Population (Refs.) & Sample & Cases & Methods & Potential role & Alteration \\
\hline $8 q 24$ & & & & & & $\uparrow$ \\
\hline $3 q 26$ & USA (9) & $\mathrm{NC}, \mathrm{CIN}, \mathrm{SCC}$ & 136 & FISH & Diagnosis & $\uparrow$ \\
\hline $3 q 26$ & Slovakia (12) & NC, LSIL, HSIL, SCC/AC & 131 & FISH & Diagnosis & $\uparrow$ \\
\hline $5 p 15$ & & & & & & $\uparrow$ \\
\hline $3 q 26$ & Greece (10) & ASCUS/LSIL & 40 & FISH & Prognosis & - \\
\hline $3 q 26$ & Norway (11) & $\mathrm{CIN} 2 / 3$ & 19 & FISH & Prognosis & - \\
\hline
\end{tabular}

NC, normal cervix; CIN, cervical intraepithelial neoplasia; SCC, squamous carcinoma of cervix; ASCUS, atypical squamous cells of undetermined significance; LSIL, low grade squamous intraepithelial lesion; HSIL, high grade squamous intraepithelial lesion; AC, adenocarcinoma; ASC, adenosquamous carcinoma; FISH, fluorescence in situ hybridization. $\uparrow$, indicates that the molecule is upregulated in cervical diseases. -, indicates that the amount of molecules was not compared in different tissues.

Table II. DNA polymorphisms in cervical disease.

\begin{tabular}{|c|c|c|c|c|}
\hline Name & Variation & Population (Refs.) & Cases & Methods \\
\hline \multicolumn{5}{|c|}{ Association with HPV infection } \\
\hline FOXP3 & rs3761548, rs2232365 & Brazil (13) & 426 & PCR \\
\hline TP53 & rs1042522 & Kyrgyz (14) & 205 & PCR \\
\hline \multicolumn{5}{|c|}{ Association with cancer susceptibility } \\
\hline POLR2E & rs3787016 & China (15) & 884 & PCR \\
\hline$A P O B E C 3 G$ & rs5757465 & Uygur (16) & 529 & First-generation \\
\hline$I L 1 B$ & rs1143627 & Uygur (17) & 569 & PCR \\
\hline$N Q O 1$ & rs1800566 & China (18) & 1,018 & PCR \\
\hline CTLA4 & rs5742909 & Asian (19) & 8,507 & Meta $^{\mathrm{a}}$ \\
\hline$D U T$ & rs3784619, rs11637235 & China (20) & 2,000 & PCR \\
\hline \multicolumn{5}{|c|}{ Association with CIN3 susceptibility } \\
\hline FOXP3 & rs3761548 & Brazil (13) & 426 & PCR \\
\hline$D U T$ & rs3784619, rs11637235 & China (20) & 2,000 & PCR \\
\hline
\end{tabular}

FOXP3, forkhead box P3; TP53, tumor protein p53; POLR2E, polymerase II polypeptide E; APOBEC3G, apolipoprotein B mRNA editing enzyme-catalytic polypeptide-like 3G; IL1B, interleukin-1 $\beta ; N Q O 1, \mathrm{NAD}(\mathrm{P}) \mathrm{H}$ : Quinone oxidoreductase 1; CTLA4, cytotoxic T-lymphocyte associated antigen-4; DUT, deoxyuridine triphosphatase; PCR, polymerase chain reaction. ${ }^{a}$ Meta-analysis study.

\section{Histone modifications}

Histone modifications involve processes in which histones undergo acetylation, methylation or other modifications under the action of related enzymes. Upon analyzing the expression levels of histone $\mathrm{H} 3$ acetyl $\mathrm{K} 9$ (H3K9ac) and histone $\mathrm{H} 3 \mathrm{tri}$ methyl K4 (H3K4me3) in cervical cancer, Beyer et al (27) discovered that both histones were related to the clinicopathological variables of patients. In addition, the staining intensity of $\mathrm{H} 3 \mathrm{~K} 9 \mathrm{ac}$ was also identified to be associated with the 10-year survival rate. These findings revealed the important role of histone acetylation and methylation in cervical cancer. Zhang et al (28) also discovered that HPV 18 E6/E7 enhanced the transcriptional activity of enhancer of zeste homolog 2 (EZH2), thereby enhancing the expression levels of histone 3 tri methyl K27 (H3K27me3) and exerting a positive effect on the development of cervical cancer. Polycomb repressive complex 2 (PRC2) can also catalyze the methylation of histones, thereby inhibiting gene expression. Shi et al (29) identified C10ORF12 as an interactor of PRC2, which was found to positively regulate $\mathrm{H} 3 \mathrm{~K} 27 \mathrm{me} 3$ modifications. At present, inhibitors for enzymes controlling histone modifications have been developed and are being used in clinical cancer treatment (30). However, to the best of our knowledge, related studies in cervical cancer are rare. Therefore, further research into histone modifications in cervical cancer is required.

\section{6. miRNA alterations}

Zeng et al (31) compared the expression levels of nine miRNAs in normal cervical, LSIL, HSIL and cervical cancer tissues; the results revealed that in cervical cancer, miR-218 expression levels were downregulated by 0.175 -fold $(\mathrm{P}=0.002)$, while miR-21 expression levels were upregulated by 5.677 -fold $(\mathrm{P}=0.001)$ compared with the normal tissues. Zhu et al (32) discovered that the upregulation of miR-21-5p 
Table III. DNA methylation in cervical disease.

\begin{tabular}{|c|c|c|c|c|c|}
\hline Name & Population (Refs.) & Sample & Cases & Methods & Alteration \\
\hline \multicolumn{5}{|l|}{$D L X 4$} & $\uparrow$ \\
\hline SIM1 & Japan (21) & NC, CIN, SCC & 113 & PCR, IHC & $\uparrow$ \\
\hline$P A X 1$ & $\operatorname{Meta}^{\mathrm{a}}(22)$ & $\mathrm{NC}, \mathrm{CIN}, \mathrm{SCC} / \mathrm{AC}$ & 1,055 & Meta $^{\mathrm{a}}$ & $\downarrow$ \\
\hline MEG3 & China (23) & NC, CIN, SCC, AC & 168 & MSP & $\uparrow$ \\
\hline hsa-miR-124-2 & Brazil (24) & $\mathrm{NC}, \mathrm{CIN}$ & 447 & PCR & $\uparrow$ \\
\hline \multicolumn{5}{|l|}{ SOX1 } & $\uparrow$ \\
\hline \multicolumn{5}{|l|}{ TERT } & $\uparrow$ \\
\hline \multicolumn{5}{|l|}{$L M X 1 A$} & $\uparrow$ \\
\hline GHSR & The Netherlands (25) & NC, CIN, SCC & 233 & NGS & $\uparrow$ \\
\hline \multicolumn{5}{|l|}{$S S T$} & $\uparrow$ \\
\hline \multicolumn{5}{|l|}{ ZICl } & $\uparrow$ \\
\hline FAM19A4/miR-124-2 & The Netherlands (26) & LSIL & 1,040 & PCR & - \\
\hline \multicolumn{6}{|c|}{$\begin{array}{l}D L X 4 \text {, distal-less homeobox } 4 \text {; SIM1, SIM bHLH transcription factor } 1 ; P A X 1 \text {, paired box gene } 1 ; M E G 3 \text {, maternally expressed } 3 \text {; } \\
S O X 1 \text {, SRY-box transcription factor } 1 ; T E R T \text {, telomerase reverse transcriptase; LMX1A, LIM homeobox transcription factor 1- } \alpha \text {; GHSR, growth } \\
\text { hormone secretagogue receptor; SST, somatostatin; ZIC1, Zic family member } 1 ; \text { FAM19A4, family with sequence similarity } 19 \text { (chemokine } \\
\text { (C-C)-motif)-like)-member A4; NC, normal cervix; CIN, cervical intraepithelial neoplasia; SCC, squamous carcinoma of cervix; AC, adenocarci- } \\
\text { noma; PCR, polymerase chain reaction; IHC, immunohistochemistry; NGS, 'next-generation' sequencing technology; MSP, methylation-specific } \\
\text { polymerase chain reaction. 'Meta-analysis study. } \uparrow \text {, indicates that the molecule is upregulated in cervical diseases; } \downarrow \text {, indicates that the molecule } \\
\text { is downregulated in cervical diseases; -, indicates that the amount of molecules was not compared in different tissues. }\end{array}$} \\
\hline
\end{tabular}

expression levels and the downregulation of miR-34a expression levels were associated with the severity of cervical lesions $(\mathrm{P}<0.05)$. In addition, miR-409-3p was negatively associated with E6 mRNA, and subsequent cell experiments revealed that it exerted an inhibitory effect on cervical cancer cells (33).

Recently, numerous studies have focused on the expression levels of miRNAs and their target genes in cervical cancer. Jin et al (34) compared the expression levels of miR-612 in normal and cancerous cervical tissues and cells, and discovered that they were downregulated in cancer tissues and cells, and that the target of miR-612 was nin one binding protein $(N O B 1)$. Zhao et al (35) reported that miR-15a-5p expression levels were upregulated in cervical cancer, and TP53 regulated inhibitor of apoptosis 1 (TP53INP1) was identified as the target gene. In fact, numerous miRNAs have been discovered to be downregulated in cervical cancer, including miR-889-3p (36), miR-299-3p (37), miR-140-3p (38), miR-505-5p (39), miR-877 (40), miR-636 (41), miR-144-3p (42), miR-139-5p (43), miR-126 (44), miR-138 (45), miR-526b (46), miR-432 (47), miR-543 (48) and miR-503 (49). Conversely, miRNAs that have been identified to be upregulated in cervical cancer include miR-93-5p (50) and miR-150-5p (51).

In addition, the detection of miRNA in the blood has also been suggested as a feasible method to diagnose cervical diseases. For example, the expression levels of miR-3142 in the serum of patients with cervical cancer were reported to be significantly upregulated compared with these levels in healthy individuals, and the high expression levels of miR-3142 were associated with a poor prognosis (52). In addition, Zheng et al (53) performed miRNA sequencing of plasma samples and screened out two significant miRNAs, let-7d-3p and miR-30d-5p; these two miRNAs were discovered to be able to distinguish between $\mathrm{CIN} 1^{-}$and $\mathrm{CIN} 2^{+}$lesions [area under the curve $(\mathrm{AUC})=0.828]$.

The details of these studies described above are presented in Table IV. It is worth mentioning that previous studies investigating the therapeutic ability of miRNAs in treating cancer have been performed, such as for the treatment of liver and breast cancer (54). However, there still remains a long way to go for the clinical application of miRNAs for the treatment of cervical cancer.

\section{Protein alterations}

The effect of the p16INK4a (p16), Ki-67 and cytokeratin 7 (CK7) proteins have been studied in cervical cancer and precancerous lesions. p16 is a tumor-suppressor protein that serves an important role in cell cycle regulation by decelerating the progression of cells from the $G_{1}$ phase to $S$ phase. $\mathrm{Ki}-67$ is a protein that is present during the active phase of the cell cycle and is involved in the proliferative activity of tumors. High p16 expression levels and $>50 \%$ of Ki-67 expression in CIN2 lesions was discovered to have a higher probability of progressing to CIN3 and cancerous lesions $(\mathrm{P}<0.001)$, with a hazard ratio of 2.58 and 2.84 , respectively (55). Another study demonstrated that all of the HSIL/CIN2 patients with p16-negative expression had either regressed to normal or CIN1 tissue during the 12 months of follow-up, while both persistent and progressive CIN2 lesions were p16-positive (56). Therefore, these findings suggested that p16 and Ki-67 may be used to predict the outcome of CIN2.

While it is controversial to predict the outcome of CIN1, a follow-up study of an average of 28 months revealed that p16 staining had limited value in predicting the progression of LSILs to higher-grade lesions (57).In addition,HPV16/18 was discovered 
Table IV. miRNAs in cervical disease.

\begin{tabular}{|c|c|c|c|c|c|c|}
\hline Name & Population (Refs.) & Sample & Cases & Methods & Target gene & Alteration \\
\hline miR-612 & China (34) & $\mathrm{NC}, \mathrm{CC}$ & 52 & PCR & $N O B 1$ & $\downarrow$ \\
\hline $\operatorname{miR}-15 a-5 p$ & China (35) & $\mathrm{NC}, \mathrm{CC}$ & 30 & PCR & TP53INP1 & $\uparrow$ \\
\hline miR-889-3p & China (36) & $\mathrm{NC}, \mathrm{CC}$ & 49 & PCR & $F G F R 2$ & $\downarrow$ \\
\hline miR-299-3p & China (37) & Cell lines & 0 & PCR & $T C F 4$ & $\downarrow$ \\
\hline miR-140-3p & China (38) & $\mathrm{NC}, \mathrm{CC}$ & 44 & PCR & $R R M 2$ & $\downarrow$ \\
\hline miR-505-5p & China (39) & $\mathrm{NC}, \mathrm{CC}$ & 60 & PCR & $C D K 5$ & $\downarrow$ \\
\hline miR-877 & China (40) & $\mathrm{NC}, \mathrm{CC}$ & 57 & PCR & $M A C C 1$ & $\downarrow$ \\
\hline miR-636 & China (41) & $\mathrm{NC}, \mathrm{CC}$ & 40 & PCR & $B C L 2, C D K 6$ & $\downarrow$ \\
\hline miR-144-3p & China (42) & $\mathrm{NC}, \mathrm{CC}$ & 23 & PCR & МАРК & $\downarrow$ \\
\hline miR-139-5p & China (43) & $\mathrm{NC}, \mathrm{CC}$ & 40 & PCR & TCF4 & $\downarrow$ \\
\hline miR-126 & China (44) & $\mathrm{NC}, \mathrm{CC}$ & 30 & PCR & ZEBI & $\downarrow$ \\
\hline miR-138 & China (45) & Cell lines & 0 & PCR & $H 2 A X$ & $\downarrow$ \\
\hline $\operatorname{miR}-526 b$ & China (46) & $\mathrm{NC}, \mathrm{SCC}, \mathrm{AC}$ & 85 & PCR & $P B X 3$ & $\downarrow$ \\
\hline miR-432 & China (47) & $\mathrm{NC}, \mathrm{CC}$ & 47 & PCR & FN1 & $\downarrow$ \\
\hline miR-543 & China (48) & $\mathrm{NC}, \mathrm{SCC}, \mathrm{AC}$ & 69 & PCR & TRPM7 & $\downarrow$ \\
\hline miR-503 & China (49) & $\mathrm{NC}, \mathrm{CC}$ & 52 & PCR & $A K T 2$ & $\downarrow$ \\
\hline miR-93-5p & China (50) & $\mathrm{NC}, \mathrm{CIN}, \mathrm{CC}$ & 328 & PCR & BTG3 & $\uparrow$ \\
\hline miR-150-5p & China (51) & Cell lines & 0 & PCR & SRCIN1 & $\uparrow$ \\
\hline
\end{tabular}

NC, normal cervix; CIN, cervical intraepithelial neoplasia; SCC, squamous carcinoma of cervix; CC, cervical cancer; AC, adenocarcinoma; PCR, polymerase chain reaction; FISH, fluorescence in situ hybridization. $\uparrow$, indicates that the molecule is upregulated in cervical diseases. $\downarrow$, indicates that the molecule is downregulated in cervical diseases.

to be more capable of predicting LSIL progression compared with other HR-HPVs; however, there was no association identified between p16/Ki-67 staining and prognosis (58). Therefore, further research is required for p16 and Ki67. In addition, other previous p16-related research has been conducted (59-61).

Cytokeratin 7 (CK7) is a squamocolumnar junction-related immunomarker. Paquette et al (62) identified that CK7-positive LSILs progressed with more ease to HSILs compared with negative CK7 LSILs (32.0 vs. 11.1\%; $\mathrm{P}=0.05)$. Mills et al (63) proved that high levels of CK7 staining were associated with the progression of $\mathrm{CIN} 1$ to $\mathrm{CIN} 2(\mathrm{OR}=2.8 ; \mathrm{P}=0.021)$ and to CIN3 (OR=5.7; $\mathrm{P}=0.018)$. Cao et al (64) also reported the role of CK7 in CIN.

$\mathrm{Wu}$ et al (65) determined that the expression levels of cancerous inhibitor of PP2A (CIP2A) increased alongside the development of cervical lesions. CIP2A could bind to the oncogene H-Ras and activate the MEK/ERK signaling pathway, which subsequently promoted epithelial-mesenchymal transition (EMT) in cervical cancer progression. Human discs large tumor suppressor (DLG1) is a component of the Scribble polarity complex; through a 2-year follow-up study, Cavatorta et al (66) identified that the cases progressing from LSILs to HSILs had diffuse DLG1 expression, and that LSILs with a DLG1 staining pattern similar to normal tissue were more likely to regress. Myosin IB (MYO1B) is a member of class I myosin, which was discovered to participate in the cell migration of zebrafish embryonic cells. In addition, MYO1B expression levels were upregulated in squamous cervical cancer and cervical cancer cell lines, where it served a role in cancer cell proliferation, migration and invasion (67).
A previous study investigating the expression levels of multiple proteins in exfoliated cervical cells indicated that the expression levels of Sialyl-Lewis A in cervical cancer were significantly downregulated compared with normal and CIN lesions $(\mathrm{P}<0.01)$. In addition, the expression of HPV L1 and p53 in cervical cancer were increased compared with normal and CIN lesions $(\mathrm{P}<0.05)(68)$. Compared with normal cervical tissue, the expression of $\mathrm{T}$ lymphoma invasion and metastasis 1 (Tiam1) was significantly increased in CIN and cervical cancer $(\mathrm{P}<0.05$ and $\mathrm{P}<0.01$, respectively), and the upregulated expression levels of Tiam1 were discovered to be associated with a poor prognosis in patients with cervical cancer. In addition, Tiam1 promoted the proliferation and migration of cancer cells by activating EMT (69). Mizushima et al discovered that following the development of normal cervical tissue to $\mathrm{CIN}$, as the severity of the lesions increased, the expression of atypical protein kinase $\mathrm{C} \lambda / \mathrm{\iota}(\mathrm{aPKC} \lambda / \mathrm{\iota})$ also increased. In fact, $\mathrm{aPKC} \lambda / \mathrm{\iota}$ overexpression and nuclear localization were identified as independent factors for CIN1 progression, with hazard ratios of $4.26(\mathrm{P}=0.007)$ and $3.59(\mathrm{P}=0.019)$, respectively (70). Hester et al also discovered that prostaglandin E2-receptor 3 (EP3) expression was decreased with increasing grades of cervical lesions (from normal to CIN1-3; $\mathrm{P}<0.05$ ). Notably, the proportion of EP3-positive cells in progressed CIN2 was decreased compared with in regressed CIN2 $(\mathrm{P}=0.04)(71)$.

In recent years, numerous studies have been conducted to determine the relationship between protein levels in the blood and cervical diseases. Sawada et al (72) found that patients with cervical cancer with high levels of vascular endothelial 
Table V. Protein alterations in cervical disease.

\begin{tabular}{|c|c|c|c|c|c|}
\hline Name & Population (Refs.) & Sample & Cases & Methods & Alteration \\
\hline \multicolumn{6}{|c|}{ Potential diagnosis markers } \\
\hline p16 & Italy (59) & CIN1/3 & 66 & IHC & $\uparrow$ \\
\hline p16 & China (61) & $\mathrm{NC}, \mathrm{CIN}, \mathrm{SCC}$ & 254 & WB & $\uparrow$ \\
\hline CK7 & USA (62) & NC, CIN, SCC & 326 & IHC & $\uparrow$ \\
\hline CK7 & & & & & $\downarrow$ \\
\hline HPV L1 & China (64) & LSIL, HSIL & 100 & $\mathrm{IHC}$ & $\uparrow$ \\
\hline CIP2A & China (65) & NC, CIN, SCC & 105 & PCR, IHC, WB & $\uparrow$ \\
\hline MYO1B & China (67) & NC, CIN, SCC & 335 & IHC & $\downarrow$ \\
\hline SLeA & Korea (68) & $\mathrm{NC}, \mathrm{CIN}, \mathrm{CC}$ & 146 & ELISA, WB, IP & $\uparrow$ \\
\hline HPV L1 & & & & & $\uparrow$ \\
\hline p53 & & & & & $\uparrow$ \\
\hline Tiam1 & China (69) & $\mathrm{NC}, \mathrm{CIN}, \mathrm{CC}$ & 298 & IHC & $\uparrow$ \\
\hline $\mathrm{aPKC} \lambda / \mathrm{\iota}$ & Japan (70) & $\mathrm{NC}, \mathrm{CIN}$ & 205 & IHC & $\uparrow$ \\
\hline EP3 & Germany (71) & $\mathrm{NC}, \mathrm{CIN}$ & 124 & IHC & $\downarrow$ \\
\hline RAP1 & Brazil (74) & $\mathrm{NC}, \mathrm{CIN}$ & 183 & IHC & $\uparrow$ \\
\hline $\mathrm{COX}-2$ & & & & & $\uparrow$ \\
\hline EGFR & Brazil (75) & NC, CIN, SCC & 412 & $\mathrm{IHC}$ & $\uparrow$ \\
\hline NCL & China (76) & NC, CIN, SCC & 175 & IHC & $\uparrow$ \\
\hline HBXIP & China (77) & NC, CIN, SCC & 243 & IHC & $\uparrow$ \\
\hline ERK1/2 & China (78) & NC, CIN, SCC & 176 & PCR, IHC & $\uparrow$ \\
\hline $\mathrm{A} 3 \mathrm{G}$ & Japan (79) & NC, CIN, SCC & 34 & PCR, IHC & $\uparrow$ \\
\hline HPV 16 & & & & & $\uparrow$ \\
\hline hnRNP K & China (80) & $\mathrm{NC}, \mathrm{CIN}$ & 204 & FH, WB & $\uparrow$ \\
\hline MFN2 & Korea (81) & NC, CIN, SCC & 191 & $\mathrm{IHC}$ & $\uparrow$ \\
\hline ADAR1 & China (82) & NC, CIN, SCC & 303 & IHC & $\uparrow$ \\
\hline Geminin & China (83) & $\mathrm{NC}, \mathrm{CIN}$ & 95 & IHC & $\uparrow$ \\
\hline SIRT1 & USA (84) & CIN, SCC & 101 & IHC & $\uparrow$ \\
\hline Gankyrin & China (85) & NC, CIN, SCC & 76 & IHC & $\uparrow$ \\
\hline \multicolumn{6}{|c|}{ Potential prognosis markers for CIN1 } \\
\hline HPV16/18 & Spain (58) & LSIL & 200 & $\mathrm{IHC}$ & - \\
\hline HPV L1 & Italy (59) & CIN1/3 & 66 & IHC & $\downarrow$ \\
\hline \multicolumn{6}{|l|}{ p16 } \\
\hline HPV L1 & Japan (60) & CIN & 199 & PCR, IHC & - \\
\hline CK7 & USA (62) & NC, CIN, SCC & 326 & $\mathrm{IHC}$ & $\uparrow$ \\
\hline CK7 & USA (63) & CIN1 & 517 & $\mathrm{IHC}$ & - \\
\hline CK7 & & & & & $\uparrow$ \\
\hline HPV L1 & China (64) & LSIL, HSIL & 100 & $\mathrm{IHC}$ & $\downarrow$ \\
\hline DLG1 & Argentina (66) & LSIL & 30 & IHC & - \\
\hline $\mathrm{aPKC} \lambda / \mathrm{\imath}$ & Japan (70) & $\mathrm{NC}, \mathrm{CIN}$ & 205 & IHC & $\uparrow$ \\
\hline RAP1 & Brazil (74) & $\mathrm{NC}, \mathrm{CIN}$ & 183 & $\mathrm{IHC}$ & $\uparrow$ \\
\hline \multicolumn{6}{|c|}{ Potential prognosis markers for CIN2 } \\
\hline p16/Ki-67 & Japan (55) & CIN2 & 122 & $\mathrm{IHC}$ & - \\
\hline p16 & Spain (56) & HSIL/CIN2 & 96 & IHC & - \\
\hline \multicolumn{6}{|l|}{ p16 } \\
\hline HPV L1 & Japan (60) & CIN & 199 & PCR, IHC & - \\
\hline EP3 & Germany (71) & $\mathrm{NC}, \mathrm{CIN}$ & 124 & IHC & $\downarrow$ \\
\hline
\end{tabular}

NC, normal cervix; CIN, cervical intraepithelial neoplasia; SCC, squamous carcinoma of cervix; CC, cervical cancer; LSIL, low grade squamous intraepithelial lesion; HSIL, high grade squamous intraepithelial lesion; IHC, immunohistochemistry; PCR, polymerase chain reaction; WB, western blot analysis; ELISA, enzyme linked immunosorbent assay; IP, immunoprecipitation; FH, flow-through hybridization; $\uparrow$, indicates that the molecule is upregulated in cervical diseases; $\downarrow$, indicates that the molecule is downregulated in cervical diseases; -, indicates that the amount of molecules was not compared in different tissues. 
growth factor A (VEGF-A) and vascular endothelial growth factor receptor 2 (VEGFR-2) in the serum had a poor prognosis. Maestri et al (73) discovered that the serum levels of MBL-associated serine proteases (MASP)-2, MASP-1 and MAP-19 in patients with cervical cancer were significantly upregulated compared with in CIN and normal tissues $(\mathrm{P}<0.0001$, $\mathrm{P}=0.012, \mathrm{P}=0.025$, respectively). These findings indicated that detecting the levels of specific proteins in the blood may help diagnose and predict the prognosis of cervical diseases.

Other proteins discovered to be involved in cervical cancer and precursors include RAS proximate 1 (RAP1) (74), cyclooxygenase-2 (Cox-2), epidermal growth factor receptor (EGFR), human epidermal growth factor receptor-2 (ERBB-2) (75), nucleolin (NCL) (76), hepatitis B virus X-interacting protein (HBXIP) (77), extracellular signal-regulated kinas $1 / 2$ (ERK1/2) (78), APOBEC3G (79), heterogeneous nuclear ribonucleoproteins K (hnRNP K) (80), mitofusin-2 (MFN2) (81), RNA-dependent adenosine deaminase (ADAR1) (82), geminin (83), sirtuin 1 (SIRT1) (84) and gankyrin (85), among others. The details of these molecules are listed in Table V.

\section{Conclusion}

A significant amount of research has accumulated regarding the possible development of biomarkers for the early diagnosis of cervical lesions and the risk assessment of precursors. The development of cervical cancer is a multifactorial process; the transition from normal cervix tissue to precursors/cervical cancer is associated with chromosomal alterations, DNA polymorphisms, the DNA methylation status, histone modifications, and alterations to miRNA and protein expression levels. The majority of the experimental studies are conducted using cervical tissues and cells, while a small number of specimens are studied in the blood of patients. Since liquid biopsies represent a detection method with demonstrated diagnostic and monitoring value for cancer, which exert little harm to the body due to the non-invasive nature, they warrant further research in the future. Although there has been significant progress in the field of cervical cancer research, the identification of important molecules that could help predict the progression and prognosis of cervical cancer are still required. However, future studies require more samples and improved experimental designs.

\section{Acknowledgements}

Not applicable.

\section{Funding}

The present study was funded by teacher grants from Central South University (Changsha, Hunan, China).

\section{Availability of data and materials}

Not applicable.

\section{Author's contributions}

JS and YX wrote the manuscript and constructed the tables. LS and $\mathrm{QH}$ designed and revised the manuscript. JS, YX, LS and
$\mathrm{QH}$ were responsible for the submission of the manuscript and the final approval of the version to be published. All authors were involved in the literature search and review.

\section{Ethics approval and consent to participate}

Not applicable.

\section{Patient consent for publication}

Not applicable.

\section{Competing interests}

The authors declare that they have no competing interests.

\section{References}

1. Bray F, Ferlay J, Soerjomataram I, Siegel RL, Torre LA and Jemal A: Global cancer statistics 2018: GLOBOCAN estimates of incidence and mortality worldwide for 36 cancers in 185 countries. CA Cancer J Clin 68: 394-424, 2018.

2. Chen W, Zheng R, Baade PD, Zhang S, Zeng H, Bray F, Jemal A, $\mathrm{Yu}$ XQ and He J: Cancer statistics in China, 2015. CA Cancer J Clin 66: 115-132, 2016.

3. Schiffman M, Wentzensen N, Wacholder S, Kinney W, Gage JC and Castle PE: Human papillomavirus testing in the prevention of cervical cancer. J Natl Cancer Inst 103: 368-383, 2011.

4. zur Hausen H: Papillomaviruses and cancer: From basic studies to clinical application. Nat Rev Cancer 2: 342-350, 2002.

5. Lu Z and Chen J: Introduction of WHO classification of tumours of female reproductive organs, fourth edition. Zhonghua Bing $\mathrm{Li}$ Xue Za Zhi 43: 649-650, 2014 (In Chinese).

6. Dalla Palma P, Giorgi Rossi P, Collina G, Buccoliero AM, Ghiringhello B, Gilioli E, Onnis GL, Aldovini D, Galanti G, Casadei G, et al: The reproducibility of CIN diagnoses among different pathologists: Data from histology reviews from a multicenter randomized study. Am J Clin Pathol 132: 125-132, 2009.

7. Zhang SK, Kang LN, Chang IJ, Zhao FH, Hu SY, Chen W, Shi JF, Zhang X, Pan QJ, Li SM and Qiao YL: The natural history of cervical cancer in Chinese women: Results from an 11-year follow-up study in China using a multistate model. Cancer Epidemiol Biomarkers Prev 23: 1298-1305, 2014.

8. Tainio K, Athanasiou A, Tikkinen KAO, Aaltonen R, Cardenas J, Hernandes, Glazer-Livson S, Jakobsson M, Joronen K, Kiviharju M, et al: Clinical course of untreated cervical intraepithelial neoplasia grade 2 under active surveillance: Systematic review and meta-analysis. BMJ 360: k499, 2018.

9. Policht FA, Song M, Sitailo S, O'Hare A, Ashfaq R, Muller CY, Morrison LE, King W and Sokolova IA: Analysis of genetic copy number changes in cervical disease progression. BMC Cancer 10: 432, 2010.

10. Rodolakis A, Biliatis I, Symiakaki H, Kershnar E, Kilpatrick MW, Haidopoulos D, Thomakos N and Antsaklis A: Role of chromosome 3q26 gain in predicting progression of cervical dysplasia. Int J Gynecol Cancer 22: 742-747, 2012.

11. Koeneman MM, Ovestad IT, Janssen EAM, Ummelen M, Kruitwagen RFPM, Hopman AH and Kruse AJ: Gain of chromosomal region $3 \mathrm{q} 26$ as a prognostic biomarker for high-grade cervical intraepithelial neoplasia: Literature overview and pilot study. Pathol Oncol Res 25: 549-557, 2019.

12. Kudela E, Visnovsky J, Balharek T, Farkasova A, Zubor P, Plank L and Danko J: Different amplification patterns of 3q26 and 5p15 regions in cervical intraepithelial neoplasia and cervical cancer. Ann Diagn Pathol 35: 16-20, 2018.

13. Cezar-Dos-Santos F, Ferreira RS, Okuyama NCM, Trugilo KP, Sena MM, Pereira ER, Pereira APL, Watanabe MAE and de Oliveira KB: FOXP3 immunoregulatory gene variants are independent predictors of human papillomavirus infection and cervical cancer precursor lesions. J Cancer Res Clin Oncol 145: 2013-2025, 2019.

14. Isakova J, Vinnikov D, Bukuev N, Talaibekova $\mathrm{E}$ and Aldasheva N: TP53 Codon 72 polymorphism and human papilloma virus-associated cervical cancer in Kyrgyz women. Asian Pac J Cancer Prev 20: 1057-1062, 2019. 
15. Chen B, Jiao Y, Yaolong F, Li T, Liu Y, Wang M, Xiuli G and Feng X: The POLR2E rs3787016 polymorphism is strongly associated with the risk of female breast and cervical cancer. Pathol Res Pract 215: 1061-1065, 2019.

16. Sui S, Chen H, Han L, Wang L, Niyazi M and Zhu K: Correlation of APOBEC 3G polymorphism with human papillomavirus (HPV) persistent infection and progression of cervical lesions. Med Sci Monit 25: 6990-6997, 2019.

17. Wang L, Zhao W, Hong J, Niu F, Li J, Zhang S and Jin T: Association between IL1B gene and cervical cancer susceptibility in Chinese Uygur population: A case-control study. Mol Genet Genomic Med 7: e779, 2019.

18. Yang S, Zhao J and Li L: NAD(P)H: Quinone oxidoreductase 1 gene rs1800566 polymorphism increases the risk of cervical cancer in a Chinese Han sample: A STROBE-complaint case-control study. Medicine (Baltimore) 99: e19941, 2020.

19. Hu S, Pu D, Xia X, Guo B and Zhang C: CTLA-4 rs5742909 polymorphism and cervical cancer risk: A meta-analysis. Medicine (Baltimore) 99: e19433, 2020.

20. Ye F, Wang H, Liu J, Cheng Q, Chen X and Chen H: Genetic variants of the dUTPase-encoding gene DUT increase HR-HPV infection rate and cervical squamous cell carcinoma risk. Sci Rep 9: 513, 2019.

21. Sakane J, Taniyama K, Miyamoto K, Saito A, Kuraoka K, Nishimura T, Sentani K, Oue N and Yasui W: Aberrant DNA methylation of DLX4 and SIM1 is a predictive marker for disease progression of uterine cervical low-grade squamous intraepithelial lesion. Diagn Cytopathol 43: 462-470, 2015.

22. Luan T, Hua Q, Liu X, Xu P, Gu Y, Qian H, Yan L, Xu X, Geng R, Zeng X and Li P: PAX1 methylation as a potential biomarker to predict the progression of cervical intraepithelial neoplasia: A Meta-analysis of related studies. Int J Gynecol Cancer 27: 1480-1488, 2017

23. Zhang J, Yao T, Lin Z and Gao Y: Aberrant Methylation of MEG3 functions as a potential plasma-based biomarker for cervical cancer. Sci Rep 7: 6271, 2017.

24. Rogeri CD, Silveira HCS, Causin RL, Villa LL, Stein MD, de Carvalho AC, Arantes LM, Scapulatempo-Neto C, Possati-Resende JC, Antoniazzi M, et al: Methylation of the hsa-miR-124, SOX1, TERT, and LMX1A genes as biomarkers for precursor lesions in cervical cancer. Gynecol Oncol 150: 545-551, 2018

25. Verlaat W, Snijders PJ, Novianti PW, Wilting SM, De Strooper LM, Trooskens G, Vandersmissen J, Van Criekinge W, Wisman GB, Meijer CJ, et al: Genome-wide DNA methylation profiling reveals methylation markers associated with $3 \mathrm{q}$ gain for detection of cervical precancer and cancer. Clin Cancer Res 23: 3813-3822, 2017.

26. De StrooperLM,Berkhof J, Steenbergen RD, Lissenberg-Witte BI Snijders PJ, Meijer CJ and Heideman DA: Cervical cancer risk in HPV-positive women after a negative FAM19A4/mir124-2 methylation test: A post hoc analysis in the POBASCAM trial with 14 year follow-up. Int J Cancer 143: 1541-1548, 2018.

27. Beyer S, Zhu J, Mayr D, Kuhn C, Schulze S, Hofmann S, Dannecker C, Jeschke U and Kost BP: Histone H3 Acetyl K9 and Histone H3 Tri Methyl K4 as prognostic markers for patients with cervical cancer. Int J Mol Sci 18: 477, 2017.

28. Zhang L, Tian S, Pei M, Zhao M, Wang L, Jiang Y, Yang T, Zhao J, Song L and Yang X: Crosstalk between histone modification and DNA methylation orchestrates the epigenetic regulation of the costimulatory factors, Tim 3 and galectin9, in cervical cancer. Oncol Rep 42: 2655-2669, 2019.

29. Shi Y, Ma HL, Zhuang YW, Wang XX, Jiang Y and Xu HE: C10ORF12 modulates PRC2 histone methyltransferase activity and H3K27me3 levels. Acta Pharmacol Sin 40: 1457-1465, 2019.

30. Egger G, Liang G, Aparicio A and Jones PA: Epigenetics in human disease and prospects for epigenetic therapy. Nature 429: 457-463, 2004

31. Zeng K, Zheng W, Mo X, Liu F, Li M, Liu Z, Zhang W and Hu X Dysregulated microRNAs involved in the progression of cervical neoplasm. Arch Gynecol Obstet 292: 905-913, 2015.

32. Zhu Y, Han Y, Tian T, Su P, Jin G, Chen J and Cao Y: MiR-21-5p, miR-34a, and human telomerase RNA component as surrogate markers for cervical cancer progression. Pathol Res Pract 214: 374-379, 2018

33. Sommerova L, Anton M, Bouchalova P, Jasickova H, Rak V, Jandakova E, Selingerova I, Bartosik M, Vojtesek B and Hrstka R: The role of miR-409-3p in regulation of HPV16/18-E6 mRNA in human cervical high-grade squamous intraepithelial lesions. Antiviral Res 163: 185-192, 2019.

34. Jin Y,Zhou X, Yao X, Zhang Z, Cui M and Lin Y: MicroRNA-612 inhibits cervical cancer progression by targeting NOB1. J Cell Mol Med 24: 3149-3156, 2020.
35. Zhao XQ, Tang H, Yang J, Gu XY, Wang SM and Ding Y: MicroRNA-15a-5p down-regulation inhibits cervical cancer by targeting TP53INP1 in vitro. Eur Rev Med Pharmacol Sci 23: 8219-8229, 2019

36. Sun Y, Cheng Y, Zhang Y and Han K: MicroRNA-889-3p targets FGFR2 to inhibit cervical cancer cell viability and invasion. Exp Ther Med 18: 1440-1448, 2019.

37. Yu Y, Zhao JD and Yang H: MiR-299-3p inhibits proliferation and invasion of cervical cancer cell via targeting TCF4. Eur Rev Med Pharmacol Sci 23: 5621-5627, 2019.

38. Ma J, Zhang F and Sun P: miR-140-3p impedes the proliferation of human cervical cancer cells by targeting RRM2 to induce cell-cycle arrest and early apoptosis. Bioorg Med Chem 28: $115283,2020$.

39. Kapora E, Feng S, Liu W, Sakhautdinova I, Gao B and Tan W: MicroRNA-505-5p functions as a tumor suppressor by targeting cyclin-dependent kinase 5 in cervical cancer. Biosci Rep 39: BSR20191221, 2019.

40. Meng F, Ou J, Liu J, Li X, Meng Y, Yan L, Deng P and Sun B: MicroRNA-877 is downregulated in cervical cancer and directly targets MACC1 to inhibit cell proliferation and invasion. Exp Ther Med 18: 3650-3658, 2019.

41. Hu QL, Xu ZP, Lan YF and Li B: miR-636 represses cell survival by targeting CDK6/Bcl-2 in cervical cancer. Kaohsiung J Med Sci 36: 328-335, 2020

42. Wu J, Zhao Y, Li F and Qiao B: MiR-144-3p: A novel tumor suppressor targeting MAPK6 in cervical cancer. J Physiol Biochem 75: 143-152, 2019.

43. Ji X, Guo H, Yin S and Du H: miR-139-5p functions as a tumor suppressor in cervical cancer by targeting TCF4 and inhibiting Wnt $/ \beta$-catenin signaling. Onco Targets Ther 12: 7739-7748, 2019.

44. Xu J, Wang H, Wang H, Chen Q, Zhang L, Song C, Zhou Q and Hong Y: The inhibition of miR-126 in cell migration and invasion of cervical cancer through regulating ZEB1. Hereditas 156: 11, 2019.

45. Yuan M, Zhao S, Chen R, Wang G, Bie Y, Wu Q and Cheng J: MicroRNA-138 inhibits tumor growth and enhances chemosensitivity in human cervical cancer by targeting H2AX. Exp Ther Med 19: 630-638, 2020

46. Li H, Wang J, Xu F, Wang L, Sun G, Wang J and Yang Y: By downregulating PBX3, miR-526b suppresses the epithelial-mesenchymal transition process in cervical cancer cells. Future Oncol 15: 1577-1591, 2019.

47. Wang S, Gao B, Yang H, Liu X, Wu X and Wang W: MicroRNA-432 is downregulated in cervical cancer and directly targets FN1 to inhibit cell proliferation and invasion. Oncol Lett 18: 1475-1482, 2019.

48. Liu X, Gan L and Zhang J: miR-543 inhibites cervical cancer growth and metastasis by targeting TRPM7. Chem Biol Interact 302: 83-92, 2019.

49. Fu Y, Meng Y, Gu X, Tian S, Hou X and Ji M: miR-503 expression is downregulated in cervical cancer and suppresses tumor growth by targeting AKT2. J Cell Biochem: Jan 29, 2019 (Epub ahead of print). doi: 10.1002/jcb.28099.

50. Li J, Chu ZP, Han H, Zhang Y, Tian F, Zhang JQ and Huang XH: Suppression of miR-93-5p inhibits high-risk HPV-positive cervical cancer progression via targeting of BTG3. Hum Cell 32: 160-171, 2019.

51. Zhu J and Han S: miR-150-5p promotes the proliferation and epithelial-mesenchymal transition of cervical carcinoma cells via targeting SRCIN1. Pathol Res Pract 215: 738-747, 2019.

52. Luo Q, Wang H and Li J: Serum miR-3142 could be used as a potential biomarker to screen cervical cancer patients from healthy controls. Clin Lab 65, 2019.

53. Zheng M, Hou L, Ma Y, Zhou L, Wang F, Cheng B, Wang W, Lu B, Liu P, Lu W and Lu Y: Exosomal let-7d-3p and miR-30d-5p as diagnostic biomarkers for non-invasive screening of cervical cancer and its precursors. Mol Cancer 18: 76, 2019.

54. Hayes J, Peruzzi PP and Lawler S: MicroRNAs in cancer: Biomarkers, functions and therapy. Trends Mol Med 20: 460-469, 2014.

55. Miyamoto S, Hasegawa J, Morioka M, Hirota Y, Kushima M and Sekizawa A: The association between p16 and Ki-67 immunohistostaining and the progression of cervical intraepithelial neoplasia grade 2. Int J Gynaecol Obstet 134: 45-48, 2016.

56. Miralpeix E, Genoves J, Maria Sole-Sedeno J, Mancebo G, Lloveras B, Bellosillo B, Alameda F and Carreras R: Usefulness of p16(INK4a) staining for managing histological high-grade squamous intraepithelial cervical lesions. Mod Pathol 30: 304-310, 2017. 
57. Sagasta A, Castillo P, Saco A, Torne A, Esteve R, Marimon L, Ordi J and Del Pino M: p16 staining has limited value in predicting the outcome of histological low-grade squamous intraepithelial lesions of the cervix. Mod Pathol 29: 51-59, 2016.

58. Rodriguez-Trujillo A, Marti C, Angeles MA, Sierra A, Esteve R, Saco A, Barnadas E, Marimon L, Nicolas I, Torne A, et al: Value of HPV 16/18 genotyping and p16/Ki-67 dual staining to predict progression to HSIL/CIN2 ${ }^{+}$in negative cytologies from a colposcopy referral population. Am J Clin Pathol 150: 432-440, 2018.

59. Negri G, Bellisano G, Zannoni GF, Rivasi F, Kasal A, Vittadello F Antoniazzi S, Faa G, Ambu R and Egarter-Vigl E: p16 ink4a and HPV L1 immunohistochemistry is helpful for estimating the behavior of low-grade dysplastic lesions of the cervix uteri. Am J Surg Pathol 32: 1715-1720, 2008.

60. Hoshikawa S, Sano T, Yoshida T, Ito H, Oyama T and Fukuda T: Immunohistological analysis of HPV L1 capsid protein and p16 protein in low-grade dysplastic lesions of the uterine cervix Pathol Res Pract 206: 816-820, 2010.

61. Jia WL, Ding L, Ren ZY, Wu TT, Zhao WM, Fan SL and Wang JT: Effects of both folic acid, p16 protein expression and their interaction on progression of cervical cancerization. Zhonghua Liu Xing Bing Xue Za Zhi 37: 1647-1652, 2016 (In Chinese).

62. Paquette C, Mills AM and Stoler MH: Predictive value of cytokeratin 7 immunohistochemistry in cervical low-grade squamous intraepithelial lesion as a marker for risk of progression to a high-grade lesion. Am J Surg Pathol 40: 236-243, 2016.

63. Mills AM, Paquette C, Terzic T, Castle PE and Stoler MH: CK7 immunohistochemistry as a predictor of CIN1 progression: A retrospective study of patients from the quadrivalent HPV vaccine trials. Am J Surg Pathol 41: 143-152, 2017.

64. Cao L, Sun PL, Yao M, Chen S and Gao H: Clinical significance of CK7, HPV-L1, and koilocytosis for patients with cervical low-grade squamous intraepithelial lesions: A retrospective analysis. Hum Pathol 65: 194-200, 2017.

65. Wu Y, Gu TT and Zheng PS: CIP2A cooperates with H-Ras to promote epithelial-mesenchymal transition in cervical-cancer progression. Cancer Lett 356: 646-655, 2015.

66. Cavatorta AL, Di Gregorio A, Bugnon Valdano M, Marziali F, Cabral M, Bottai H, Cittadini J, Nocito AL and Gardiol D: DLG1 polarity protein expression associates with the disease progress of low-grade cervical intraepithelial lesions. Exp Mol Pathol 102: 65-69, 2017.

67. Zhang HR, Lai SY, Huang LJ, Zhang ZF, Liu J, Zheng SR, Ding K, Bai X and Zhou JY: Myosin $1 \mathrm{~b}$ promotes cell proliferation, migration, and invasion in cervical cancer. Gynecol Oncol 149: 188-197, 2018

68. Jin Y, Kim SC, Kim HJ, Ju W, Kim YH and Kim HJ: Use of protein-based biomarkers of exfoliated cervical cells for primary screening of cervical cancer. Arch Pharm Res 41: 438-449, 2018

69. Yang Y, Wu Q, Li N, Che S, Jin T, Nan Y, Lin Z and Chen L: Upregulation of Tiam1 contributes to cervical cancer disease progression and indicates poor survival outcome. Hum Pathol 75: $179-188,2018$.

70. Mizushima T, Asai-Sato M, Akimoto K, Nagashima Y, Taguri M, Sasaki K, Nakaya MA, Asano R, Tokinaga A, Kiyono T, et al: Aberrant expression of the cell polarity regulator aPKC $\lambda / \mathrm{\iota}$ is associated with disease progression in cervical intraepithelial neoplasia (CIN): A possible marker for predicting CIN prognosis. Int J Gynecol Pathol 35: 106-117, 2016.
71. Hester A, Ritzer M, Kuhn C, Schmoeckel E, Mayr D, Kolben T, Dannecker C, Mahner S, Jeschke U and Kolben TM: The role of EP3-receptor expression in cervical dysplasia. J Cancer Res Clin Oncol 145: 313-319, 2019.

72. Sawada M, Oishi T, Komatsu H, Sato S, Chikumi J, Nonaka M, Kudoh A, Osaku D and Harada T: Serum vascular endothelial growth factor A and vascular endothelial growth factor receptor 2 as prognostic biomarkers for uterine cervical cancer. Int J Clin Oncol 24: 1612-1619, 2019.

73. Maestri CA, Nisihara R, Mendes HW, Jensenius J, Thiel S, Messias-Reason I and de Carvalho NS: MASP-1 and MASP-2 serum levels are associated with worse prognostic in cervical cancer progression. Front Immunol 9: 2742, 2018.

74. Pascoal-Xavier MA, Figueiredo AC, Gomes LI, Peruhype-Magalhaes V, Calzavara-Silva CE, Costa MA, Reis IA, Bonjardim CA, Kroon EG, Oliveira JG and Ferreira PC: RAP1 GTPase overexpression is associated with cervical intraepithelial neoplasia. PLoS One 10: e0123531, 2015.

75. Fukazawa EM, Baiocchi G, Soares FA, Kumagai LY, Faloppa CC, Badiglian-Filho L, Coelho FR, Goncalves WJ, Costa RL and Goes JC: Cox-2, EGFR, and ERBB-2 expression in cervical intraepithelial neoplasia and cervical cancer using an automated imaging system. Int J Gynecol Pathol 33: 225-234, 2014.

76. Meng GZ, Zi Y, Li HQ, Huang M and Gao T: Nucleolin expression is correlated with carcinogenesis and progression of cervical squamous cell carcinoma. Nan Fang Yi Ke Da Xue Xue Bao 35: 1511-1514, 2015 (In Chinese).

77. Li N, Wang Y, Che S, Yang Y, Piao J, Liu S and Lin Z: HBXIP over expression as an independent biomarker for cervical cancer. Exp Mol Pathol 102: 133-137, 2017.

78. Fan SL, Ding L, Ren ZY, Chen X, Sun XS, Li CC, Liu CL, Jia WL, Li QL and Wang JT: Effect of extracellular signal-regulated kinas 1/2 expression and HPV16 infection and their interaction in progression of cervical cancerization. Zhonghua Liu Xing Bing Xue Za Zhi 38: 96-101, 2017 (In Chinese).

79. Iizuka T, Wakae K, Nakamura M, Kitamura K, Ono M, Fujiwara $\mathrm{H}$ and Muramatsu M: APOBEC $3 \mathrm{G}$ is increasingly expressed on the human uterine cervical intraepithelial neoplasia along with disease progression. Am J Reprod Immunol 78, 2017.

80. Ding L, Feng MJ, Liu CL, Wang L, Song ZC, Yang Q, Li XX, Song L, Gao W and Wang JT: Effect of hnRNP K and its interaction with HPV16 on cervical intraepithelial neoplasia. Zhonghua Liu Xing Bing Xue Za Zhi 39: 1630-1635, 2018 (In Chinese).

81. Ahn SY, Li C, Zhang X and Hyun YM: Mitofusin-2 expression is implicated in cervical cancer pathogenesis. Anticancer Res 38: 3419-3426, 2018

82. Chen Y, Wang H, Lin W and Shuai P: ADAR1 overexpression is associated with cervical cancer progression and angiogenesis. Diagn Pathol 12: 12, 2017.

83. Xing Y, Wang C and Wu J: Expression of geminin, p16, and Ki67 in cervical intraepithelial neoplasm and normal tissues. Medicine (Baltimore) 96: e7302, 2017.

84. Velez-Perez A, Wang XI, Li M and Zhang S: SIRT1 overexpression in cervical squamous intraepithelial lesions and invasive squamous cell carcinoma. Hum Pathol 59: 102-107, 2017.

85. Liu Y, Zhang J, Qian W, Dong Y, Yang Y, Liu Z, Feng Y, Ma D, Zhang Z and Wu S: Gankyrin is frequently overexpressed in cervical high grade disease and is associated with cervical carcinogenesis and metastasis. PLoS One 9: e95043, 2014. 